\title{
A Method for Investigating the Potential Impacts of Climate Change Scenarios on Annual Minimum Groundwater Levels
}

\author{
J. P. Bloomfield, BSc, MSc, PhD, CGeol*, I. Gaus, BSc, PhD* and S. D. Wade \\ BSc, MSc, $\mathrm{PhD}$ ** \\ * British Geological Survey, Groundwater Systems and Water Quality Programme, Wallingford, \\ ** W S Atkins Water, Epsom, UK
}

\begin{abstract}
Previous approaches to assessing the impact of climate change scenarios on groundwater levels and groundwater droughts have focused on modelling specific recharge processes or phenomena. Statistical methods, however, based on correlations between historic groundwater level and rainfall time series, provide an alternative and robust approach to predicting minimum groundwater levels and droughts. For the purposes of this study groundwater droughts are defined in terms of the return period of a given groundwater level. A multiple linear regression model (regression of monthly rainfall totals for a given period against values of minimum annual groundwater levels for the same period) when used with synthetic rainfall data based on climate change scenarios, enables changes in future annual groundwater level minima to be modelled. The method is illustrated at three sites on the Chalk, Permo-Triassic sandstone and Jurassic limestone aquifers.
\end{abstract}

Key words: climate change; groundwater levels; groundwater drought; return period analysis; UK aquifers 


\section{Introduction}

Climate change affects the hydrological cycle and has an uncertain impact on groundwater resources. There is a clear need to understand and assess the importance of climate change both at the scale of catchments and of public supply sources, and to assess the possible risks posed to groundwater resources under different climate change scenarios ${ }^{(1)}$. These risks include, at one extreme, the potential degradation of groundwater-fed ecosystems and the potential reduction of source yields due to low groundwater levels associated with groundwater droughts. At the other extreme they could include possible groundwater flooding with associated implications for infrastructure damage and deleterious effects on water quality under conditions of high seasonal or shorter duration intense rainfall. The work described in this paper aims to reduce uncertainty associated with predicting the impact of climate change on groundwater levels during groundwater droughts. The general approach may be used to predict the magnitude and return period of other extreme events associated with groundwater level changes. A quantitative method has also been developed as part of a larger project investigating source yield under

drought conditions ${ }^{(2)}$, to predict the impact of climate change on annual minimum groundwater levels.

There is increasing evidence to suggest that at least part of the observed recent change in the global climate is due to a human-induced rise in atmospheric concentrations of greenhouse gases ${ }^{(3)}$. The inertia in global systems 
means that this climate-forcing is likely to continue for the foreseeable future, even if the rate of greenhouse gas release to the atmosphere is reduced. The weather in the UK is not immune to these changes ${ }^{(3)}$. The current UK climate, particularly rainfall, is noted for its short-term variability around a relatively stationary mean, while sustained periods of very wet or very dry weather are relatively rare. Historical observations show that this pattern has been characteristic of the last two centuries.

Recent years, however, have seen two phenomena that suggest that the UK climate pattern may be changing. One is a trend of rising temperature, at a rate that is unlikely to be due solely to natural climatic variations. The 1990s (up until 1998) were almost consistently about $0.5{ }^{\circ} \mathrm{C}$ warmer than the $1961-1990$ average, and four of the five warmest years in the 340-year Central England Temperature series occurred between 1988 and $1997^{(3)}$. The other phenomenon is the apparent increasing frequency of 'extreme' climatic events. For example, the extended and marked reduction in effective rainfall across almost all of Britain during 1984, 1989 and 1995 is one type of extreme event. These conditions would be expected only once in 200 years $^{(4)}$ based on analysis of historical records. It should be noted that it is difficult to establish a causal association between anthropogenic induced climate change and specific 'extreme' events (add CEH / Met Office ref), however, the increased frequency of such events is predicted by many climate change models. Climate scenarios produced by the UK Climate Impacts Programme (UKCIP) suggest that these trends will continue $^{(3)}$. If they do continue, what are the implications for groundwater 
droughts in the UK during the next few decades? Is there any reason to suppose that extreme events will increase in frequency and / or severity?

To date there have been few studies of the potential impacts of climate change on groundwater resources and none that have provided robust quantitative methods or tools for investigating the effect of climate change on groundwater levels across a range of hydrogeological settings. Most groundwater studies have formed part of broader investigations that generally concentrate on the potential impacts on surface water resources under different future climate scenarios $^{(5,6)}$.

Early studies reviewed the frequency and magnitude of both 'winter' and 'summer' droughts induced by climate change and assessed their gross effects on groundwater resources ${ }^{(7,8)}$. More recently, a number of studies have used process-based recharge models to try and quantify the changes in groundwater resources under a range of climate change scenarios $^{(9,10,11,12)}$. They have emphasized how some aquifers may be more sensitive to climate changes than others. For example, Price ${ }^{(4)}$ noted that variation in groundwater storage characteristics is an important factor in mitigating the impacts of droughts caused by climate change. Despite this work, however, it has proved difficult to develop flexible non-site specific models of groundwater level response to climate change due to a reliance on process-based recharge models. This problem has been avoided in the present study by using a statistical correlation between rainfall and groundwater level data. The method described in this paper quantifies historical relationships between groundwater levels and rainfall in such a way that 
synthetic rainfall data generated for a range of climate change scenarios can then be used with calibrated groundwater hydrographs to predict future groundwater levels.

\section{Groundwater droughts and the problem of predicting annual groundwater minima}

\section{Groundwater droughts}

A range of rainfall-based drought indices have been developed to provide a means of quantifying drought based on monthly rainfall data. For example, the standard precipitation index $(\mathrm{SPI})^{(13)}$ provides an estimate of the magnitude and severity of rainfall droughts of selected durations. Estimation of groundwater droughts, however, is not so simple. Groundwater droughts can be considered in terms of a period of minimum groundwater storage. They can be considered in environmental terms as a period of minimum baseflow, in terms of water supply as a period of minimum groundwater level at a supply source, or in terms of water demand as a period of maximum stress at a groundwater source $e^{(2)}$.

For the purposes of the present study a critical period groundwater drought is defined as the groundwater level at a representative observation borehole that equals the 1 in $x$ year annual minimum groundwater level, where $x$ is specified by the operator or researcher. For example, a 1 in 20 year return period may be appropriate for operational planning at an observation borehole, 
but a 1 in 50, or even a 1 in 100 year groundwater drought might be used as the design criteria when planning new public supply sources or infrastructure. Given this definition, graphs of minimum annual groundwater levels against return period (return period graphs) provide the most complete description of critical period groundwater droughts for a given borehole. Return period graphs have been used in this study to present the predicted groundwater levels for a range of climate change scenarios.

\section{Predicting annual groundwater level minima}

The central problem in predicting the severity of groundwater droughts, and specifically annual groundwater level minima, under different climate scenarios is how to predict recharge. As noted earlier, reliance on process-based recharge models to predict changes in groundwater level have meant that it has not been possible to develop flexible non-site specific models of groundwater level response to climate change. The process-based recharge models have generally been based on assumptions regarding specific recharge process that may not be valid under different climatic conditions. The studies were generally site specific and are not easy to apply over a wide range of hydrogeological settings and across a variety of aquifer types. It is also difficult to undertake cross comparison of results from different studies. In addition, many use derived parameters such as potential evapotranspiration (PET) and soil moisture deficit (SMD). 
Uncertainties associated with these derived values are propagated through the models and are difficult to quantify.

The method adopted in the present study avoids these problems and is based on a simple statistical correlation between groundwater levels and rainfall $^{(14)}$. It has the additional benefit that the errors associated with the correlation are easily quantified. The basic modelling strategy that has been adopted was developed by Bennett ${ }^{(14)}$ and is a multiple linear regression (MLR) model that consists of a regression of monthly rainfall totals for a given period against values of minimum annual groundwater levels for the same period. The model is flexible and could be extended to include other regression parameters such as mean monthly temperature or evapotranspiration if these time series are available. The statistical approach enables the effects of different climate scenarios to be modelled using different synthetic rainfall series. The following section describes the MLR method and shows how the calibrated regression can be used to predict annual groundwater minima and construct groundwater drought return curves.

\section{Methodology}

\section{MLR method}

The MLR method uses groundwater level data based on the hydrometric year. The hydrometric year usually runs from April to March so that nearly all the minima occur near the middle of the hydrometric year. The annual groundwater level minima are recorded for each hydrometric year. As the MLR method uses 
monthly rainfall data, daily or weekly rainfall data can be lumped into cumulative monthly values. In this regression analysis a number of predictors (i.e. monthly rainfall) are used to predict the dependent variable (i.e. annual minimum groundwater level), but care must be taken when using the MLR approach. The predictors used in the regression analysis must be independent; i.e. one month's rainfall should not be highly correlated with rainfall during the subsequent month. A Pearson correlation matrix ${ }^{18}$ is generated to characterize the degree of correlation between rainfall in successive months and each correlation is tested for significance using the t-test. If significant correlation is found between successive monthly rainfall data then the assumptions behind the MLR no longer hold. One way round this problem is to add two months rainfall where there is a significant correlation and test for correlation between the summed rainfall and rainfall for the subsequent month. If this correlation is not significant then the summed rainfall can be used instead of the monthly rainfall. In addition, the dependent variable should not show significant autocorrelation. This is tested by calculating an autocorrelation function for the annual groundwater level minima.

If these assumptions can be satisfied the MLR can be performed. For the purposes of this study the annual minimum groundwater level was taken to be linearly dependent on fifteen monthly rainfall measurements, usually between January in one year and March the following year (the hydrometric year plus the three preceding months). An expression with the following form is obtained;

$$
Z_{\text {min }}=\beta_{1} R_{\text {Jano }}+\beta_{2} R_{\text {Feb0 }}+\beta_{3} R_{\text {Maro }}+\beta_{4} R_{A p r} \ldots+\beta_{15} R_{\text {Mar }}+c
$$


where $Z_{\min }$ is the minimum annual groundwater level in the hydrometric year, $R_{A p r}$ $\ldots R_{\text {Mar }}$ are the monthly rainfalls throughout the hydrometric year and $R_{\text {Jano }}, R_{\text {Febo, }}$ and $R_{\text {Maro }}$ are the rainfall in last three months of the preceding year. $\beta_{1}$ to $\beta_{15}$ are the fifteen regression coefficients and $c$ is a constant.

For each regression, a measure of the fit of the regression to the observations is given by the value of $R^{2}$. This indicates what percentage of the variance is accounted for by the model. In multiple linear regression models the $R^{2}$ statistic can be improved by using more predictors, i.e. more months rainfall, but even though a better fit may be obtained with the calibrated data the resulting model may not be any better at predicting future water levels. It is, therefore, common to quote the adjusted $R^{2}$ statistic, $R_{a}{ }^{2}$. This statistic takes into account both the goodness of fit of the model and the number of predictors used.

A smaller number of predictors could be used in the MLR model. For example, a systematic approach to the selection of the number of predictors would be to investigate the Pearson correlation between monthly rainfall and minimum groundwater levels to see how many months rainfall prior to a groundwater level minimum are significant. This approach, however, could not be used for forward modelling purposes because, for any given future year, there is no way of predicting in which month the annual groundwater level minimum would occur and which months predicted rainfall should be used. Hence, a minimum of twelve months rainfall, i.e. twelve predictors, are needed for the forward model. Given the unlikely event that the annual minimum may fall right at the start of a hydrometric year, the addition of three other predictors at the end of 
the preceding hydrometric year provide a robust fifteen-month MLR model for prediction. Because fifteen predictors are being used the model requires a minimum of 16 years of rainfall and groundwater level data, although additional studies not reported here suggest that at least 20 years of time series data are required for this approach to be effective.

Once a regression has been obtained the observed monthly rainfall can be used with the regression coefficients and constant to calculate annual groundwater level minima. These calculated values can be compared with observed annual minima to give an estimate of the accuracy of the model.

\section{Prediction of climate change impacts}

To predict annual groundwater level trends under different climate change scenarios it is necessary to generate synthetic rainfall series. These are obtained by perturbing historic rainfall data using changes in long-term mean rainfall and changes in the rainfall variability for different UKCIP scenarios. Using this technique, sufficiently long synthetic rainfall series, of the order of 10,000 years, are generated. These long synthetic rainfall series are needed to enable return periods of up to 1 in 200 year drought events to be estimated with a probability of $0.05 \%$ or better. Once the long synthetic rainfall time series have been obtained, the synthetic rainfall data can be used with the MLR regression coefficients and constant to calculate predicted annual groundwater level minima. The return 
period analysis of the annual groundwater level minima is simply based on the cumulative distribution function of the predicted annual minima ${ }^{(2)}$.

\section{Site descriptions and results}

\section{The sites}

The model has been applied to three sites, one on the Chalk aquifer at Little Bucket Farm (TR 1225 4690), one on the Permo-Triassic sandstone aquifer at Bussels No.7A (SX 9528 9872), and one on the Jurassic Limestones at New Red Lion (TF 0885 3034) (Figure 1).

The borehole at Little Bucket Farm is sited on Middle Chalk. The maximum recorded water level is $+86.87 \mathrm{~m} \mathrm{OD}$, less than $0.5 \mathrm{~m}$ below the top of the borehole that is $0.6 \mathrm{~m}$ above the ground surface. The minimum recorded rest water level is $+56.77 \mathrm{~m} \mathrm{OD}$, close to the bottom of the borehole. These levels are consistent with those seen in other boreholes in the area. The hydrograph has an annual sinusoidal appearance with a mean annual range of $13.17 \mathrm{~m}$. There are no licensed groundwater abstractions within $2 \mathrm{~km}$ of the well.

The borehole at Bussels No.7A is sited on a river terrace above the Dawlish Sandstone (part of the Exeter Group of Permian age). The maximum recorded rest water level is $+25.28 \mathrm{~m}$ OD and the minimum $+22.91 \mathrm{~m}$ OD. This is consistent with water levels recorded in other boreholes in the region. The hydrograph has an annual sinusoidal appearance with an annual range of $2.2 \mathrm{~m}$. 
There are ten licensed groundwater abstractions from within $2 \mathrm{~km}$ of the borehole. Their effects on the Bussels No.7A hydrograph are unknown.

The New Red Lion borehole is lined from the surface to a depth of $25.0 \mathrm{~m}$ where it penetrates the Lincolnshire Limestone beneath the Blisworth Limestone. The Lincolnshire Limestone is about $28 \mathrm{~m}$ thick in this area, with its top at about + 9m OD. The maximum recorded rest water level for New Red Lion is $+20.7 \mathrm{~m}$ $\mathrm{OD}$ and the minimum $+5.68 \mathrm{~m} \mathrm{OD}$. The highest water levels, therefore, rise to a level within the overlying Blisworth Limestone, which is cased out; but the minimum levels are within the Lincolnshire Limestone. The hydrograph has a well-defined annual sinusoidal appearance with a mean annual range of $7.9 \mathrm{~m}$. There is one licensed groundwater abstraction within $2 \mathrm{~km}$ and is not thought to affect water levels in the observation well.

\section{Data sets used in the study}

Three data sets have been used in the study; groundwater level data, historic rainfall data, and UKCIP climate change scenarios. The groundwater level data has been taken from the National Groundwater Level Archive held by the British Geological Survey (BGS) in Wallingford. The Archive contains long-term

groundwater level records for a monitoring network of 175 boreholes each measured either weekly or monthly to the nearest $10 \mathrm{~mm}$ or better. Data and 
statistics that are available for each borehole include a site name, hydrometric area (river catchment), national grid reference, measured groundwater level, period of record, and mean, maximum, and minimum annual groundwater level ranges. Full listings of sites in the archive can be found in the Hydrogeological Data UK Yearbook ${ }^{(15)}$ and have been described by Doorgakant ${ }^{(16)}$.

Two types of rainfall data were used; rain gauge data and catchment averaged data. A long-term rain gauge record was supplied by the Environment Agency for the Street End gauge (ref. no. 664420001) for use with the Little Bucket Farm groundwater hydrograph. At the other two sites catchment averaged rainfall was used. This was supplied by the Centre for Ecology and Hydrology. The two catchments that were used were CMR 45001 Exe at Thorverton and CMR 30014 Pointon Lode at Pointon for Bussels No.7A and New Red Lion respectively ${ }^{(15)}$.

The synthetic rainfall data was generated using climate change (rainfall) scenarios taken from the UKCIP $10 \mathrm{~km}$ grid data on the UKCIP CD ROM ${ }^{(17)}$. Four scenarios have been used in the modelling, the 2020s, 2050s and 2080s medium high $(\mathrm{MH})$ scenarios and the 2080 s high scenario.

\section{Results}

$R_{a}{ }^{2}$ values of $0.47,0.51$, and 0.84 have been obtained for the regression models for Little Bucket Farm, New Red Lion and Bussels No.7A respectively. These indicate that between about $50 \%$ and $85 \%$ of the variance in the data is 
explained by the MLR models. Because, however, the models are based on different length time series it is not possible to directly compare them using their respective $R_{a}{ }^{2}$ values. One way to contrast the relative effectiveness of the MLR results between the sites is to compare the observed and calculated annual groundwater level minima for each of the three sites, Figure 2. The figure shows that the MLR models appear to provide good fits to the observed data. Averaged normalized differences (where differences are normalized by dividing by the maximum range in annual minima at a site) between observed and modelled annual groundwater level minima are 10\%, 10\% and 3\% for Little Bucket Farm, New Red Lion and Bussels No.7A respectively. Although the models provide good fits to the historic data, it is not possible to quantify how well they perform when predicting groundwater levels outside the calibration period, i.e. how well they describe future groundwater level minima that may lie outside the range of historic minima. However, this is true of most models used for forward prediction.

Figure 3 shows the results of the return period analysis for annual minimum groundwater levels for the 2020s, 2050s and 2080s medium high, and for the 2080s high scenarios as well as the observed historic data for the three sites. For example, the return period curves for Little Bucket Farm show that an annual minimum groundwater level of $57.7 \mathrm{~m} \mathrm{AOD} \mathrm{has} \mathrm{a} \mathrm{historic} \mathrm{return} \mathrm{period} \mathrm{of}$ 10 years. This return period falls to between 9 and 5 years for the four climate change scenarios under consideration. Generally, at any giving site there is a small fall in annual minimum groundwater levels for a specific return period (with the exception of New Red Lion, where a small rise is predicted for annual 
minimum groundwater levels for a specific return period for some of the climate change scenarios).

Relative changes in annual groundwater level minima can be mode clearly seen in Figure 4. This figure shows the relative changes in minimum groundwater levels for the three sites (calculated as the difference between the predicted and observed annual minima divided by the mean range in minima) for the three medium high scenarios. For example, both New Red Lion and Bussels No.7A show small predicted rises in average annual minima under all three medium high scenarios. At Little Bucket Farm a very small rise is predicted for the 2020 s medium high scenario but falls in annual groundwater level minima of about $4 \%$ and $1 \%$ are predicted for the 2050 s and 2080 s medium high scenarios. This indicates that this site may be more vulnerable under these climate change scenarios than the other two sites.

The results presented in Figures 3 and 4 are intended as illustrative. A more systematic survey is being undertaken to investigate possible trends in groundwater level response as a function of aquifer type, different climate change scenarios and regional climatic variations across the UK, and site specific factors. This work will be reported at a later date. The figures, however, illustrate that even given climate change scenarios where there is a small predicted overall increase in total annual rainfall, due to changes in seasonality and increased frequency of drought events, annual groundwater level minima may fall in the future. 


\section{Conclusions}

1. Groundwater droughts may usefully be defined on the basis of groundwater levels that are equivalent to a 1 in $x$ year annual minimum groundwater level, where $x$ is a return period specified by the operator or researcher. Given this definition, graphs of minimum annual groundwater levels against return period (return period graphs) provide the most complete description of critical period groundwater droughts for a given borehole.

2. A multiple linear regression (MLR) model that uses monthly rainfall levels as the independent variables and annual groundwater level minima as the dependent variables has been developed to predict annual groundwater level minima. For practical purposes, a minimum of 16 to 20 years of time series data is required for this approach to be effective.

3. MLR models for three sites on different aquifer types can be shown to reproduce annual groundwater level minima to within $10 \%$ or better of the range of annual minima.

4. Using the MLR calibrated models and applying five different UKCIP climate change scenarios (2020s, 2050s and 2080s medium high and the 2080s high scenarios), groundwater drought return period analyses have been produced for up to 1 in 200 year events. On the basis of these forward models it is inferred that despite an overall increase in rainfall 
predicted by some climate change scenarios, changes in the seasonality and frequency of extreme events could lead to an increase in the frequency and intensity of groundwater droughts in some areas of the UK. The Chalk aquifer in southern and eastern England may be most susceptible to these effects.

5. The method presented in this paper, unlike previous recharge-based approaches, makes no assumptions regarding recharge processes. Consequently, it is applicable to a wide range of hydrologic, geological and hydrogeological settings. In addition, the method is flexible and could be used to investigate year-on-year effects or to include other independent variables such monthly temperature variations.

\section{Acknowledgements}

We would like to thank Dave Allen, Brighid O'Dochartaigh and Nick Robins for their helpful review comments. The work described in this paper formed part of the Critical Period Groundwater Yield study (AK2653/010/DG/027) sponsored by UKWIR and the Environment Agency. The UKCIP98 Climate Scenario CD-ROM was supplied under license by the Climate Impacts LINK Project (DETR Contract EPG 1/1/68) on behalf of the UKCIP and The Met. Office (Hadley Centre). This paper is published with the permission of the Director of the British Geological Survey, NERC. 


\section{References}

(1) Grey, D.R.C., Kinniburgh, D. G., Barker, J.A. and Bloomfield J. P. Groundwater in the UK: A strategic study. Issues and research needs. Groundwater Forum Report FR/GF1, Foundation for Water Research, Marlow, Buckinghamshire, 1995, 69.

(2) Gray R., Wade, S.D., Bloomfield, J.P., I Gaus and Allen D J. Critical period groundwater yield. Report to UKWIR/EA, AK/2653/010/DG/027, 2001.

(3) Hulme, M and Jenkins, G. Climate change scenarios for the United Kingdom: Summary Report. UKCIP, 1998.

(4) Price, M. Water storage and climate change in great Britain - the role of groundwater. Proc. Instn. Civ. Engrs. Wat. Marit. \& Energy, 1998, 130, March, 42.

(5) Arnell, N.W. Climate change and water resources in Britain. Climatic Change, 1998, 39, (1), 83.

(6) Arnell, N.W., Reynard, N.S., King, R., Prudhomme, C. and Branson, J. The effect of climate change on river flows and groundwater recharge: guidelines for resource assessment. Report to UKWIR/EA, 97/CL/04/11997. 1997, 55 
(7) Vaccaro, J.J. Sensitivity of groundwater recharge estimates to climate variability and change, Columbia Plateau, Washington. J. Geophys. Res. Atmos., 1992, 97, (D3), 2821.

(8) Thomsen, R. Future droughts, water shortages in parts of Western Europe. EOS. Trans. Am. Geophys. Union, 1993, 74, 14.

(9) Henriksen, H.J. Climate change and available groundwater resources the National Water Resources Model for Denmark. Proc. $2^{\text {nd }}$ Internat. Conf. On Climate and Water, Espoo, Finland, 17-20 August, 1998, 1459.

(10) Younger, P.L., Teutsh, G., Custodio, E., Elliot, T., Sauter, M., Manzano, M., Liedl, R., Clemens, T., Huckinghaus, D., Tore, C.S., Lambán, J. and Cardaso da Silva, G. Groundwater resources and climate change effects GRACE: Final Report to the European Union RTD EV5V-CT94-0471, University of Newcastle, 1997.

(11) Wilkinson, W.B. and Cooper, D.M. The response of idealized aquifer/river systems to climate change. Hydrological Sciences Journal/Journal des Sciences Hydrologiques, 1993, 38, (5), 379.

(12) Demuth, S and Stahl, K. (editors). Assessment of the regional impact of droughts in Europe. Final Report to the European Union ENV-CT97-0553, Institute of Hydrology, University of Freiburg, Germany, 2001.

(13) McKee, T.B., Doeskin, N.J. and Kleist, J. The relationship of drought frequency and duration to time scales. Proc. $8^{\text {th }}$ Conf. On Applied Climatology, January 17-22, 1993, American Meteorological Society, Boston, Massachusetts, 179. 
(14) Bennett, J. A scoping report on statistical methods for predicting groundwater levels in the UK from rainfall data, with particular emphasis on predicting annual minimum water levels from monthly rainfall data. British Geological Survey Report WD/96/50, BGS, Keyworth, Nottingham,1996.

(15) Hydrological Data UK. Hydrometric register and statistics 1991-1995. NERC, Wallingford, 1998, 207.

(16) Doorgakant, P. Groundwater level archive for England and Wales. In: Giles, J.G.R. Geological Data Management. Geol. Soc. Special Pub., 1995, 97, 137.

(17) UKCIP98 Climate Scenario CD-ROM, Climate Impacts Project, The Hadley Centre, The Meterological Office, UK. 1998

(18) Swan A R H and Sandilands M. Introduction to Geological Data Analysis. Blackwell Science, Oxford, UK. 1995 


\section{Figure captions}

Figure 1. Location map.

Figure 2. Fitted annual minima for the Little Bucket Farm (LBF), Bussels No 7A (B No.7) and for the New Red Lion (NRL) sites. Observed minimum annual groundwater levels are shown as solid symbols and modelled values are shown as open symbols.

Figure 3. Return period analysis plots for the Little Bucket Farm, Bussels No 7A and for the New Red Lion sites.

Figure 4. Percentage change in annual minimum levels at the three sites. 
Figure 1.

Title:

Creator:

ArcView Version 3.0

Preview.

This EPS picture was not saved

with a preview included in it.

Comment:

This EPS picture will print to a

PostScript printer, but not to

other types of printers. 
Figure 2.

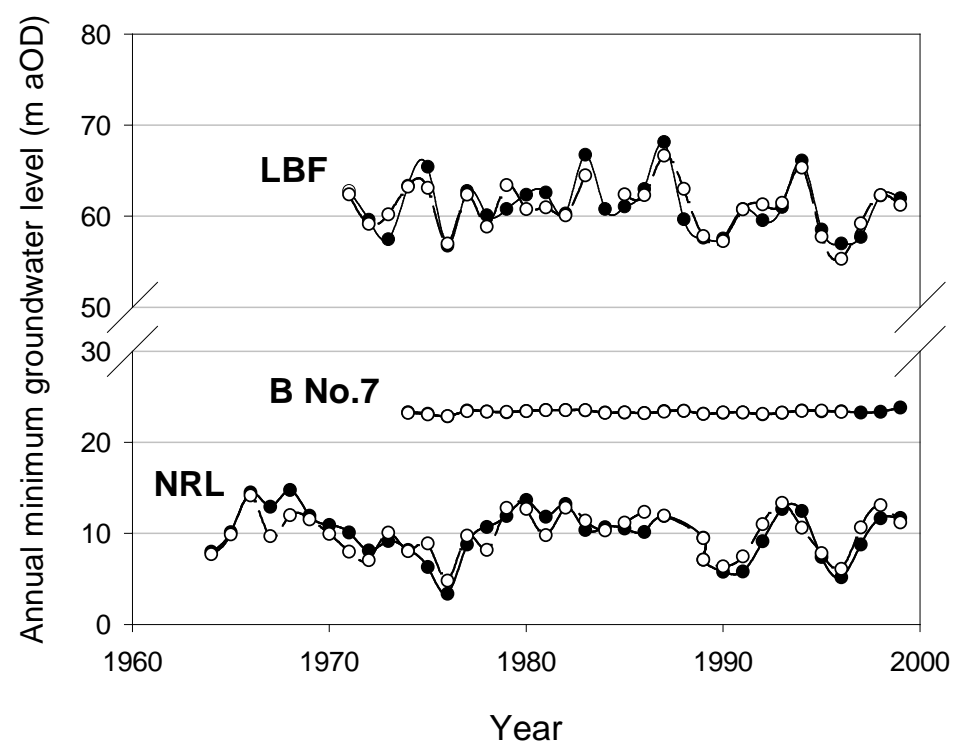


Figure 3.
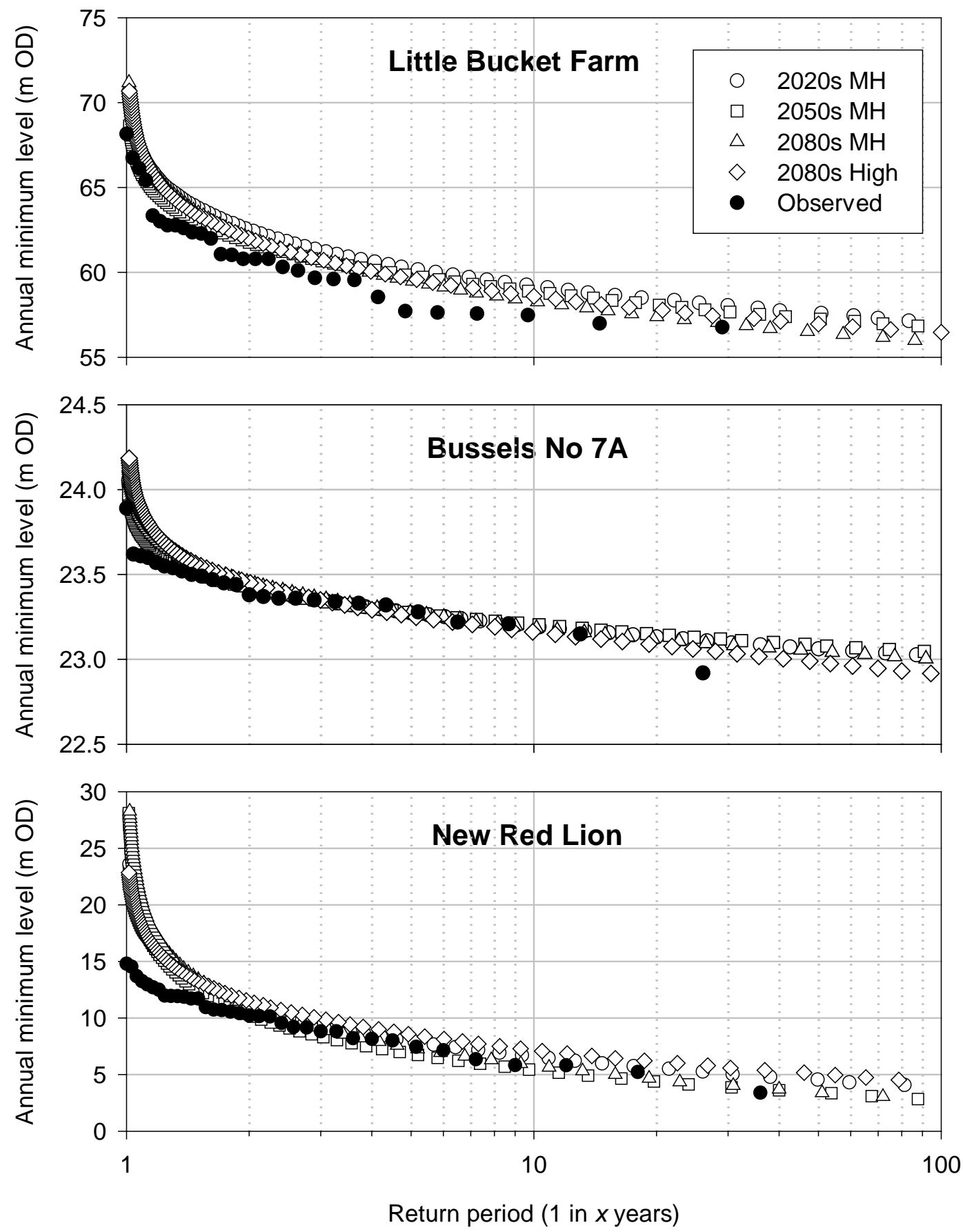
Figure 4.

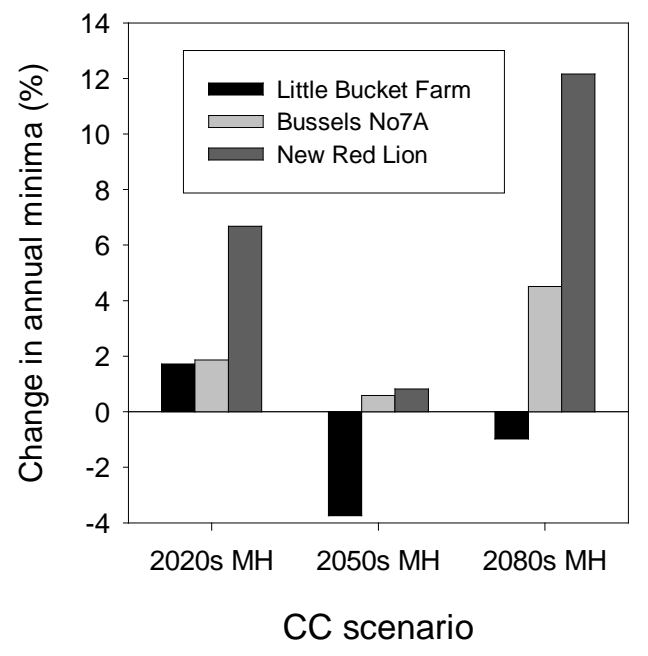

